\section{(2) \\ BRAZIILIAN JOURNAL \\ OF MEDICAL AND BIOLOGICAL RESEARCH}

www.bjournal.com.br
ISSN 0100-879X

Volume 45 (3) 179-290 March 2012

BIOMIEDICAL SCIENCES

AND

CLINICAL INVESTIGATION

Braz J Med Biol Res, March 2012, Volume 45(3) 222-229

doi: $10.1590 / \mathrm{S} 0100-879 X 2012007500024$

Association of MICA gene polymorphisms with liver fibrosis in schistosomiasis patients in the Dongting Lake region

Zheng Gong, Qi-Zhi Luo, Lin Lin, Yu-Ping Su, Hai-Bo Peng, Kun Du, Ping Yu and Shi-Ping Wang

The Brazilian Journal of Medical and Biological Research is partially financed by

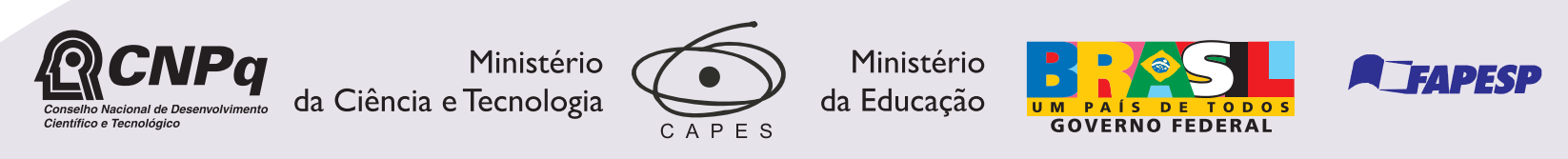

Institutional Sponsors

scielo
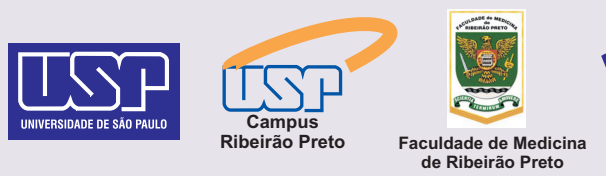

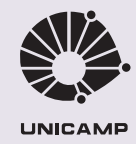

UNICAMP $\oplus$ SHIMADZU

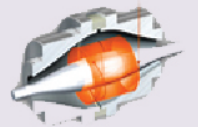

1D. Associaçāo Explore High - Performance MS Orbitrap Technology In Proteomics \& Metabolomics analitica $\underset{\text { analiticaweb.com.br }}{\text { Thermo }}$ 


\title{
Association of MICA gene polymorphisms with liver fibrosis in schistosomiasis patients in the Dongting Lake region
}

\author{
Zheng Gong1, Qi-Zhi Luo ${ }^{1}$, Lin Lin¹, Yu-Ping Su³, Hai-Bo Peng ${ }^{3}$, Kun Du¹, \\ Ping $\mathrm{Yu}^{1}$ and Shi-Ping Wang ${ }^{2}$ \\ ${ }^{1}$ Department of Immunology, College of Basic Medical Sciences, Central South University, \\ Changsha, Hunan Province, China \\ ${ }^{2}$ Key Laboratory of Schistosomiasis in Hunan, Department of Parasitology, \\ College of Basic Medical Sciences, Central South University, Changsha, Hunan Province, China \\ ${ }^{3}$ Central Blood Bank in Yueyang, Yueyang, Hunan Province, China
}

\begin{abstract}
Major histocompatibility complex class I chain-related $\mathrm{A}(M I C A)$ is a highly polymorphic gene located within the MHC class I region of the human genome. Expressed as a cell surface glycoprotein, MICA modulates immune surveillance by binding to its cognate receptor on natural killer cells, NKG2D, and its genetic polymorphisms have been recently associated with susceptibility to some infectious diseases. We determined whether MICA polymorphisms were associated with the high rate of Schistosoma parasitic worm infection or severity of disease outcome in the Dongting Lake region of Hunan Province, China. Polymerase chain reaction-sequence specific priming (PCR-SSP) and sequencing-based typing (SBT) were applied for high-resolution allele typing of schistosomiasis cases $(\mathrm{N}=103$, age range $=36.2-80.5$ years, 64 males and 39 females) and healthy controls $(\mathrm{N}=$ 141 , age range $=28.6-73.3$ years, 73 males and 68 females). Fourteen MICA alleles and five short-tandem repeat (STR) alleles were identified among the two populations. Three $\left(\mathrm{MICA}^{*} 012: 01 / 02, \mathrm{MICA}^{*} 017\right.$ and MICA*027) showed a higher frequency in healthy controls than in schistosomiasis patients, but the difference was not significantly correlated with susceptibility to $S$. japonicum infection $(\mathrm{Pc}>0.05)$. In contrast, higher MICA*A5 allele frequency was significantly correlated with advanced liver fibrosis $(\mathrm{Pc}<0.05)$. Furthermore, the distribution profile of $M I C A$ alleles in this Hunan Han population was significantly different from those published for Korean, Thai, American-Caucasian, and Afro-American populations $(P<0.01)$, but similar to other Han populations within China $(\mathrm{P}>0.05)$. This study provides the initial evidence that MICA genetic polymorphisms may underlie the severity of liver fibrosis occurring in schistosomiasis patients from the Dongting Lake region.
\end{abstract}

Key words: Schistosoma japonicum; MICA; NKG2D; Gene polymorphism; Liver fibrosis

\section{Introduction}

Schistosomiasis is the most prevalent water-borne parasitic disease worldwide and remains a major public health problem in many developing countries. Among the pathogenic Schistosoma species, S. japonicum is responsible for endemic infection in China, Indonesia, and the Philippines (1). Recorded cases of schistosomiasis in China date back more than 2100 years (2). Not surprisingly, one of the first and most substantial human health campaigns of the newly founded People's Republic of China was to control this parasitic disease. By the beginning of the 2000's, schistosomiasis had been eradicated in five of the twelve previously endemic provinces of China, accompanied by dramatic reductions in morbidity and mortality $(3,4)$.

Currently, the geographic distribution of schistosomiasis in China is primarily centered around the Yangtze River, with the worst situations in the Dongting Lake and Poyang Lake regions $(3,4)$. The Dongting Lake, located in the north of Hunan Province, is the second largest freshwater lake in China and provides an ideal habitat for Oncomelania snails, the intermediate host for S. japonicum. Sporocysts are generated in the snail and produce infective cercariae that are released from the snail into the surrounding aqueous environment. These free-swimming parasitic larvae secrete a proteolytic enzyme that facilitates penetration of

Correspondence: Ping Yu and Shi-Ping Wang, Department of Immunology, College of Basic Medical Sciences, Central South University, 110 Xiangya Road, Changsha, Hunan, China. Fax: +86-073-1448-7301. E-mail: yuping1953@hotmail.com and spwang@126.com

Received August 21, 2011. Accepted February 13, 2012. Available online March 2, 2012. Published March 19, 2012. 
the human epidermis. Inside the human host, the parasites mature in the hepatic portal vein and adult paired sex worms migrate to the mesenteric veins, depositing eggs that are carried by the circulation to the host's liver, intestine, urinary bladder or other organs. These eggs trigger the host immune response, including a localized inflammatory reaction; however, as the simple immune response is unable to clear these eggs, granuloma formation is induced to wall off the foreign substances. The granulomatous reaction is accompanied by fibrosis, which is particularly devastating to the function of liver tissues (5). Thus, the pathogenesis of schistosomiasis involves the dynamic coordination of many tissue- and processspecific genes. Undoubtedly, the parasite has evolved to exploit genes that vary in expression among different populations to establish infection.

The human major histocompatibility complex (MHC) class I chain-related (MIC) gene family consists of seven members, MICA to MICG; however, only MICA and MICB are functional genes and all other members represent pseudogenes $(6,7)$. The human MICA gene contains 6 exons encoding a cell-surface glycoprotein with three extracellular domains (encoded by exons 2, 3, and 4, respectively), a transmembrane fragment (encoded by exon 5 ), and a carboxy-terminal cytoplasmic tail (encoded by exon 6) $(6,8)$. In response to cellular stress, MICA expression is induced in many cell types, including epithelium, fibroblasts, keratinocytes, endothelial cells, and monocytes $(7,9,10)$, whereby it regulates the autoimmune response through binding to its cognate receptor (5), the natural killer (NK) cell receptor D (NKG2D) (11-16). The MICA gene is highly polymorphic, and the exons encoding the extracellular domains present the highest frequency of polymorphisms (8).

The two different types of alleles of the gene represent 76 (http://hla.alleles.org/nomenclature/stats.html) sequence alleles in the mature protein-coding region (MICA*001 to ${ }^{*} 064 \mathrm{~N}$, http://www.ebi.ac.uk/imgt/hla/ allele.html) and seven microsatellite alleles. Also known as short tandem repeats (STR), these microsatellite alleles $\left(\mathrm{MICA}^{*} \mathrm{~A} 4,{ }^{*} \mathrm{~A} 5,{ }^{*} \mathrm{~A} 5.1,{ }^{*} \mathrm{~A} 6,{ }^{*} \mathrm{~A} 7,{ }^{*} \mathrm{~A} 9\right.$, and ${ }^{*} \mathrm{~A} 10$ ) were formed by insertion/deletion of variable numbers of trinucleotide GCT repeats within exon 5 .

MICA has been identified as a candidate disease gene by several linkage disequilibrium mapping studies of common autoimmune-related diseases, including Behcet's disease, insulin-dependent diabetes mellitus, and Addison's disease (17). In our ongoing attempts to characterize the pathogenesis of schistosomiasis in the Hunan Han population, we became intrigued by the underlying mechanistic features involving autoimmune processes and hypothesized that ethnicity-related MICA polymorphisms may confer susceptibility to $S$. japonicum infection and affect the outcome of severe liver fibrosis. To this end, we performed polymerase chain reaction-sequence specific priming (PCR-SSP) and sequencing-based typing (SBT) to analyze the MICA polymorphisms in schistosomiasis patients from the Dongting Lake region and compared the distribution of MICA alleles with data for other ethnic groups around the world.

\section{Material and Methods}

\section{Subjects}

A cohort of 103 patients of Han nationality attending the Schistosomiasis Outpatient Clinic of the Teaching Hospital, School of Medical Science, Central South University (Changsha, China) between 2008 and 2010 were recruited into this study. All patients resided in Changde or Yueyang city in the Dongting Lake region, Hunan Province, China (Figure 1). All patients had a recorded clinical diagnosis of S. japonicum infection between the ages of 10 and 24 years. Diagnosis of liver fibrosis in these patients was made by B-scan ultrasonography findings fitting World Health Organization (WHO) criteria. Patients with grade 0 and grade 1 fibrosis were classified into a mild fibrotic group, and those with grade 2 (moderate) and grade 3 (severe) fibrosis into an advanced fibrotic group. For healthy controls, 141 unrelated Han individuals were recruited from the Central Blood Bank (Yueyang, China) according to the following criteria: residing in Changde or Yueyang city at the time of blood collection, no previous diagnosis of schistosomiasis, no family history of schistosomiasis, and a gender ratio match to the patient cohort. The clinicopathological features of the patients and controls are listed in Table 1. Written informed consent was obtained from each study participant, and the study was approved by the Ethics Review Board of the Central South University.

\section{High-resolution allele typing of the MICA gene by PCR-SSP and SBT}

Genomic DNA was isolated from EDTA-treated peripheral venous blood using a conventional proteinase $\mathrm{K}$ digestion/salting-out extraction method (18). The PCRSSP method was carried out as previously described with the following minor modifications (19). The human growth hormone gene was used as an internal control and amplified (834-bp fragment) by gene-specific primers (sense 5'-GCCTTCCCAACCATTCCCTTA-3' and anti-sense 5'-GAGAAAGGCCTGGAGGATTC-3') (19). Ninety-five primers targeting MICA exons 2-4 were designed according to sequences identified in a previous study (19). PCR mixtures contained 100 ng genomic DNA template, 1X PCR buffer, $200 \mu \mathrm{M}$ each deoxy-nucleoside triphosphate, $1.75 \mathrm{mM} \mathrm{MgCl}_{2}, 0.25 \cup$ Taq polymerase (all from MBI Fermentas, Lithuania), 1.5-2.0 $\mu \mathrm{M}$ allele or groupspecific primers, and $0.115 \mu \mathrm{M}$ internal control primers. PCR was carried out in an Eppendorf Mastercycler 5333 thermocycler (Germany) programmed with the following series of thermal cycling conditions: initial denaturation at 


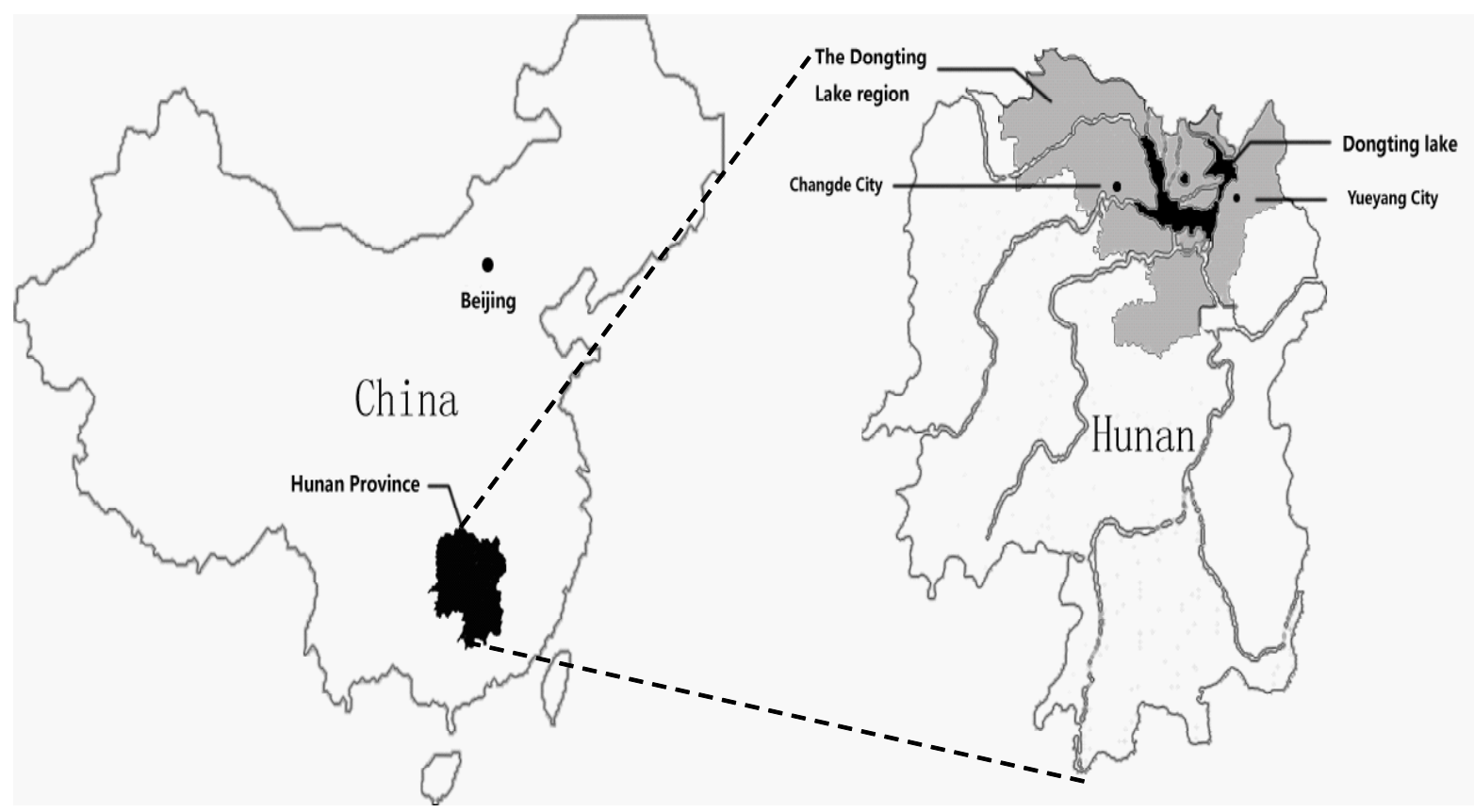

Figure 1. Map showing the relative locations of Hunan Province, the Dongting Lake region, Changde City, and Yueyang City in China.

$94^{\circ} \mathrm{C}$ for $4 \mathrm{~min} ; 10$ cycles of denaturation at $94^{\circ} \mathrm{C}$ for 30 $\mathrm{s}$, annealing at $64.5^{\circ} \mathrm{C}$ for $50 \mathrm{~s}$, and elongation at $72^{\circ} \mathrm{C}$ for $20 \mathrm{~s} ; 10$ cycles of denaturation at $94^{\circ} \mathrm{C}$ for $30 \mathrm{~s}$, annealing at $61.5^{\circ} \mathrm{C}$ for $50 \mathrm{~s}$, and elongation at $72^{\circ} \mathrm{C}$ for 30 $\mathrm{s} ; 10$ cycles of denaturing at $94^{\circ} \mathrm{C}$ for $30 \mathrm{~s}$, annealing at $60^{\circ} \mathrm{C}$ for $50 \mathrm{~s}$, and elongation at $72^{\circ} \mathrm{C}$ for $40 \mathrm{~s}$, and a final rapid cooling to $4^{\circ} \mathrm{C}$. Amplification products $(8 \mu \mathrm{L})$ were verified by electrophoretic resolution through a $2 \%$ agarose gel stained with ethidium bromide and visualized under ultraviolet (UV) illumination. Fifty-five MICA sequence alleles, including MICA*001 to MICA*050, were detectable and distinguished by the PCR-SSP analysis employed. Two notable exceptions were that $\mathrm{MICA}^{*}$ 007:01 could not be distinguished from $\mathrm{MICA}^{*} 026$, and $\mathrm{MICA}^{*} 002: 01$ could not be distinguished from MICA*020.

Since the structure of most MICA-STR alleles can be obtained from the Anthony Nolan Trust (HLA Informatics Group website: http://www.ebi.ac.uk/imgt/hla/allele.html), the sequences of the alleles genotyped above were used to determine the corresponding STR genotypes. Considering that there could be some unreported STR from known sequence alleles and that some rare alleles may not have been genotyped by the PCR-SSP method, we applied the SBT method as previously described to further differentiate MICA alleles and validate the results from PCR-SSP (20,21). A total of 45 samples were genotyped by PCR-SBT, including some randomly selected samples and all of the $\mathrm{MICA}^{*} 007: 01 / \mathrm{MICA}^{*} 026$ and $\mathrm{MICA}^{*} 002: 01 /$ MICA*020 alleles.
Table 1. Clinicopathological features of schistosomiasis patients and healthy controls.

\begin{tabular}{lcl}
\hline Characteristics & Patients (N = 103) & Controls (N=141) \\
\hline Gender, N (\%) & & \\
$\quad$ Male & $64(62.1 \%)$ & $73(51.8 \%)$ \\
$\quad$ Female & $39(37.9 \%)$ & $68(48.2 \%)$ \\
Age (years) & & \\
$\quad$ Range & $36.2-80.5$ & $28.6-73.3$ \\
Average & 55.6 & 50.3 \\
Liver fibrosis, N (\%) & & \\
$\quad$ Mild & $52(50.5 \%)$ & \\
$\quad$ Advanced & $51(49.5 \%)$ & \\
\hline
\end{tabular}

\section{Statistical analysis}

MICA allele distributions were tested for HardyWeinberg equilibrium to assess Mendelian inheritance. Statistical analysis was performed using the SPSS 11.5 statistical software (SPSS, Inc., USA). Allelic frequencies were calculated by direct counting, and statistical comparisons between groups were performed by the $x^{2}$ method, Yates' correction, or the Fisher exact test. Odds ratios $(\mathrm{OR})$ and $95 \%$ confidence intervals $(95 \% \mathrm{Cl})$ were calculated according to Woolf's method to determine disease risk in carriers of specific alleles. Bonferroni's multiple correction was used for the corrected $P(P c)$ by multiplying the $\mathrm{P}$ value by the number of statistical tests. 
A two-sided $\mathrm{P}<0.05$ value was considered to be statistically significant.

\section{Results}

\section{Association between MICA polymorphisms and susceptibility to $S$. japonicum infection in the Hunan Han population}

To determine the correlation between MICA polymorphisms and susceptibility to $S$. japonicum infection, we genotyped MICA and analyzed the frequencies of distinct MICA alleles in 103 schistosomiasis patients and 141 healthy controls. As shown in Table 2, a total of 14 MICA sequence alleles and five STR alleles were identified from the two groups. MICA*018 and MICA*023 were only present in the patient group and occurred at a low frequency (0.97 and $0.49 \%$, respectively). MICA* 017 and MICA*049 were only present in the healthy controls and occurred at a low frequency $(2.13$ and $0.71 \%$, respectively). The 10 remaining alleles were found in both groups. MICA* $A 5$ had the highest frequency in both groups $(32.04 \%$ for patients and $37.23 \%$ for healthy controls). MICA $012: 01 / 02$ allele $\left(X^{2}=3.95637, P=0.04669, O R=0.501,95 \% \mathrm{Cl}=0.251\right.$ -
1.001), MICA*017 allele $\left(X^{2}=4.43754, P=0.03516\right.$, OR $=1.022,95 \% \mathrm{Cl}=1.004-1.039)$ and $\mathrm{MICA}^{*} 027$ allele $\left(X^{2}=\right.$ $3.94081, \mathrm{P}=0.04713, \mathrm{OR}=0.242,95 \% \mathrm{Cl}=0.053-1.102$ ) showed dramatically higher frequencies in healthy controls; however, the difference from the patient groups was not statistically significant after correcting for multiple tests $(P c>0.05)$. Thus, none of the MICA alleles identified by our analysis correlated with susceptibility to $S$. japonicum infection in this population.

\section{Association between MICA polymorphisms and liver fibrosis severity in Hunan Han schistosomiasis patients}

Further analysis was carried out on the 12 MICA sequence alleles and 5 STR alleles identified in the patient group to determine the potential association between the MICA polymorphisms and liver fibrosis severity (Table 3 ). Only the MICA*A5 allele showed a significantly higher frequency in schistosomiasis patients with advanced fibrosis compared to patients with mild fibrosis $(45.10$ vs $26.92 \%, \mathrm{P}=$ $0.00656, \mathrm{Pc}=0.03279, \mathrm{OR}=2.230,95 \% \mathrm{Cl}=1.245-3.994)$. Although the MICA*010 allele also tended to occur more frequently in patients with advanced fibrosis $(P=0.03123)$,

Table 2. MICA allele frequencies in schistosomiasis patients and healthy controls.

\begin{tabular}{|c|c|c|c|c|c|c|c|}
\hline & \multicolumn{2}{|c|}{ Patients } & \multicolumn{2}{|c|}{ Controls } & \multirow[t]{2}{*}{$x^{2}$} & \multirow[t]{2}{*}{$\mathrm{P}$} & \multirow[t]{2}{*}{ Pc } \\
\hline & $\begin{array}{c}\text { No. of alleles } \\
\quad(N=206)\end{array}$ & $\begin{array}{l}\text { Allele frequency } \\
(\%)\end{array}$ & $\begin{array}{c}\text { No. of alleles } \\
\quad(\mathrm{N}=282)\end{array}$ & $\begin{array}{l}\text { Allele frequency } \\
\qquad(\%)\end{array}$ & & & \\
\hline \multicolumn{8}{|l|}{ MICA alleles } \\
\hline MICA*002:01 & 35 & 16.99 & 36 & 12.77 & 1.70867 & 0.19116 & NS \\
\hline $\mathrm{MICA}^{*} 004$ & 3 & 1.46 & 5 & 1.77 & 0.07406 & 0.78551 & NS \\
\hline $\mathrm{MICA}^{*} 007: 01 / 02$ & 2 & 0.97 & 2 & 0.71 & 0.10025 & 0.75153 & NS \\
\hline $\mathrm{MICA}^{*} 008: 01 / 02$ & 64 & 31.07 & 70 & 24.82 & 2.33093 & 0.12683 & NS \\
\hline $\mathrm{MICA}^{*} 009: 01 / 02$ & 12 & 5.83 & 11 & 3.90 & 0.98176 & 0.32176 & NS \\
\hline $\mathrm{MICA}^{*} 010$ & 43 & 20.87 & 76 & 26.95 & 2.38385 & 0.12259 & NS \\
\hline $\mathrm{MICA}^{*} 012: 01 / 02$ & 12 & 5.83 & 31 & 10.99 & 3.95637 & $0.04669^{*}$ & NS \\
\hline $\mathrm{MICA}^{*} 017$ & 0 & 0.00 & 6 & 2.13 & 4.43754 & $0.03516^{*}$ & NS \\
\hline $\mathrm{MICA}^{*} 018$ & 2 & 0.97 & 0 & 0.00 & 2.74913 & 0.09731 & NS \\
\hline $\mathrm{MICA}^{*} 019$ & 20 & 9.71 & 18 & 6.38 & 1.83367 & 0.17569 & NS \\
\hline $\mathrm{MICA}^{*} 023$ & 1 & 0.49 & 0 & 0.00 & 1.37174 & 0.24151 & NS \\
\hline $\mathrm{MICA}^{*} 027$ & 2 & 0.97 & 11 & 3.90 & 3.94081 & $0.04713^{*}$ & NS \\
\hline $\mathrm{MICA}^{*} 045$ & 10 & 4.85 & 14 & 4.96 & 0.00309 & 0.95567 & NS \\
\hline $\mathrm{MICA}^{*} 049$ & 0 & 0.00 & 2 & 0.71 & 1.46701 & 0.22582 & NS \\
\hline \multicolumn{8}{|l|}{ STR alleles } \\
\hline $\mathrm{MICA}^{\star} \mathrm{A} 4$ & 26 & 12.62 & 47 & 16.67 & 1.53133 & 0.21591 & NS \\
\hline $\mathrm{MICA}^{*} \mathrm{~A} 5$ & 66 & 32.04 & 105 & 37.23 & 1.41152 & 0.2348 & NS \\
\hline $\mathrm{MICA}^{*} \mathrm{~A} 5.1$ & 64 & 31.07 & 70 & 24.82 & 2.33093 & 0.12683 & NS \\
\hline $\mathrm{MICA}^{*} \mathrm{~A} 6$ & 18 & 8.74 & 18 & 6.38 & 0.96613 & 0.32565 & NS \\
\hline $\mathrm{MICA}^{*} \mathrm{~A} 9$ & 32 & 15.53 & 42 & 14.89 & 0.03795 & 0.84555 & NS \\
\hline
\end{tabular}

$\mathrm{NS}=$ nonsignificant. ${ }^{*} \mathrm{P}<0.05$ patients compared with controls (chi-square test). 
Table 3. MICA allele frequencies in schistosomiasis patients with liver fibrosis.

\begin{tabular}{|c|c|c|c|c|c|c|c|}
\hline & \multicolumn{2}{|c|}{ Advanced fibrotic group } & \multicolumn{2}{|c|}{ Mild fibrotic group } & \multirow[t]{2}{*}{$x^{2}$} & \multirow[t]{2}{*}{$\mathrm{P}$} & \multirow[t]{2}{*}{$\mathrm{Pc}$} \\
\hline & $\begin{array}{l}\text { No. of alleles } \\
\quad(N=102)\end{array}$ & $\begin{array}{l}\text { Allele frequency } \\
(\%)\end{array}$ & $\begin{array}{l}\text { No. of alleles } \\
\qquad(N=104)\end{array}$ & $\begin{array}{l}\text { Allele frequency } \\
(\%)\end{array}$ & & & \\
\hline \multicolumn{8}{|l|}{ MICA alleles } \\
\hline MICA*002:01 & 16 & 15.69 & 21 & 20.19 & 0.70958 & 0.39958 & NS \\
\hline $\mathrm{MICA}^{*} 004$ & 0 & 0.00 & 3 & 2.88 & 2.98579 & 0.0840 & NS \\
\hline $\mathrm{MICA}^{*} 007: 01 / 02$ & 1 & 0.98 & 1 & 0.96 & 0.00019 & 0.98899 & NS \\
\hline $\mathrm{MICA}^{*} 008: 01 / 02$ & 25 & 24.51 & 33 & 31.73 & 1.3274 & 0.24927 & NS \\
\hline $\mathrm{MICA}^{*} 009: 01 / 02$ & 5 & 4.90 & 7 & 6.73 & 0.31395 & 0.57527 & NS \\
\hline $\mathrm{MICA}^{*} 010$ & 33 & 32.35 & 20 & 19.23 & 4.64029 & $0.03123^{*}$ & NS \\
\hline $\mathrm{MICA}^{*} 012: 01 / 02$ & 4 & 3.92 & 7 & 6.73 & 0.80397 & 0.36991 & NS \\
\hline $\mathrm{MICA}^{*} 018$ & 0 & 0.00 & 1 & 0.96 & 0.98555 & 0.32083 & NS \\
\hline $\mathrm{MICA}^{*} 019$ & 11 & 10.78 & 8 & 7.69 & 0.58801 & 0.44319 & NS \\
\hline $\mathrm{MICA}^{*} 023$ & 0 & 0.00 & 1 & 0.96 & 0.98555 & 0.32083 & NS \\
\hline $\mathrm{MICA}^{*} 027$ & 2 & 1.96 & 0 & 0.00 & 2.05921 & 0.15129 & NS \\
\hline $\mathrm{MICA}^{*} 045$ & 5 & 4.90 & 2 & 1.92 & 1.39206 & 0.23806 & NS \\
\hline \multicolumn{8}{|l|}{ STR alleles } \\
\hline MICA*A4 & 10 & 9.80 & 11 & 10.58 & 0.03361 & 0.85454 & NS \\
\hline $\mathrm{MICA}^{*} \mathrm{~A} 5$ & 46 & 45.10 & 28 & 26.92 & 7.38996 & $0.00656^{*}$ & $0.03279^{*}$ \\
\hline $\mathrm{MICA}^{*} \mathrm{~A} 5.1$ & 25 & 24.51 & 34 & 32.69 & 1.68696 & 0.1940 & NS \\
\hline $\mathrm{MICA}^{*} \mathrm{~A} 6$ & 5 & 4.90 & 10 & 9.62 & 1.69453 & 0.19301 & NS \\
\hline $\mathrm{MICA}^{*} \mathrm{~A} 9$ & 16 & 15.69 & 21 & 20.19 & 0.70958 & 0.39958 & NS \\
\hline
\end{tabular}

NS = nonsignificant. ${ }^{*} \mathrm{P}<0.05$ advanced fibrotic group compared with mild fibrotic group (chi-square test).

Table 4. Comparison of the MICA allelic distributions of the Dongting Lake Han healthy population with other ethnic groups.

\begin{tabular}{lccccccc}
\hline & $\begin{array}{c}\text { Dongting } \\
\text { Lake }\end{array}$ & $\begin{array}{c}\text { Northern } \\
\text { Chinese }\end{array}$ & $\begin{array}{c}\text { Southern } \\
\text { Chinese }\end{array}$ & Korean & Thai & American-Caucasian & Afro-American \\
\hline$\chi^{2}$ & - & 22.234 & 14.367 & 38.980 & 38.680 & 43.161 & 73.575 \\
Degrees of freedom & - & 15 & 12 & 11 & 16 & 16 & 17 \\
$\mathrm{P}$ & - & 0.102 & 0.278 & $0.000^{*}$ & $0.001^{*}$ & $0.000^{*}$ & $0.000^{*}$ \\
\hline
\end{tabular}

${ }^{*} \mathrm{P}<0.05$ compared to Dongting Lake Han healthy population (chi-square test).

this trend was not statistically significant following multiple testing corrections $(\mathrm{Pc}>0.05)$.

\section{Comparison of MICA distribution between Chinese Han and other ethnic groups}

To characterize the differences in MICA gene polymorphisms between the distinct ethnic groups, which may modify the susceptibility of different groups to schistosomiasis or affect associated pathologies, we compared the distribution of MICA alleles from the healthy controls in this study to those reported for Southern and Northern Han populations $(22,23)$, as well as for Korean (24), Thai (25), American-Caucasian (23), and Afro-American populations (23). As shown in Table 4, no dramatic differences were observed in the MICA allelic distribution between the Han populations from different areas of China $(P>0.05)$. In contrast, significant differences were detected between the Han population from the Dongting Lake region and all other non-Chinese ethnic groups examined, including Koreans $\left(X^{2}=38.980, P=0.000\right)$, Thais $\left(X^{2}=38.680, P\right.$ $=0.001)$, American-Caucasians $\left(X^{2}=43.161, P=0.000\right)$, and Afro-Americans $\left(X^{2}=73.575, P=0.000\right)$. 


\section{Discussion}

Identification of candidate genes and/or specific alleles associated with susceptibility to or the progression of a disease will benefit clinical assessment of disease predisposition, early diagnosis and preventive therapeutic intervention. In this study, we report for the first time that a higher frequency of the MICA allele*A5 correlated significantly with the development of advanced liver fibrosis in schistosomiasis patients from the Dongting Lake region in Hunan Province, China. In addition, allelic distribution of MICA in the Chinese Han population is significantly different from that of many other ethnic groups in the world.

Epidemiologic studies on schistosomiasis indicate that this disease has a genetic basis. Alleles of HLA, in particular those within the HLA-DR and -DQ loci, have been correlated with advanced schistosomiasis and severe liver fibrosis outcome $(26,27)$. The human MICA gene is localized within the HLA class I region of chromosome 6, between $M I C B$ and $H L A-B$, and is known to be highly polymorphic (17). Functionally, MICA binding to NKG2D stimulates the release of interferon- $\gamma($ IFN- $\gamma$ ) from NK cells $(28,29)$. MICA polymorphisms are associated with a number of NK-involved diseases, such as viral infections and tumor development (8). In schistosomiasis patients infected with S. mansoni, IFN-y has been shown to confer a protective immune response against liver fibrosis (30). In addition, non-infected individuals over the age of 70 years from a Schistosoma endemic area have a significantly higher number of IFN- $\mathrm{Y}$-producing NK cells than their infected counterparts (31). The importance of NK cells and IFN-Y in schistosomiasis prompted us to examine whether MICA, with its polymorphic alleles, modifies propensity to schistosomiasis.

To address this question, we analyzed the MICA alleles of schistosomiasis patients and compared them with healthy controls of Han nationality from one of the most severe endemic areas in China, the Dongting Lake region. To our knowledge, this is the first study addressing the importance of MICA polymorphisms in schistosomiasis. Our analysis identified a total of 14 sequence alleles and five STR alleles among both populations, but none of these MICA alleles correlated significantly with the presence of schistosomiasis. Thus, these specific polymorphisms do not appear to pre-condition an individual to Schistosoma infection. However, several alleles, including $\mathrm{MICA}^{*} 012: 01 / 02, \mathrm{MICA}^{*} 017$, and $\mathrm{MICA}^{*} 027$, occurred at higher, yet nonsignificant, frequencies in healthy controls compared to patients. In view of the relatively small number of subjects in this study (103 subjects), it is important to determine whether these findings would be statistically significant if the cohorts were larger.

Although no statistically significant association was observed between the MICA alleles identified in both groups and susceptibility to schistosomiasis, the MICA*A5 allele did correlate with infected patients with advanced liver fibrosis. Likewise, the MICA*010 allele also showed a similar trend, but no statistically significant for multiple testing.

Liver fibrosis is a chronic change caused by the granulomatous immune response against eggs lodged in the periportal area (5). Both hepatic stellate cells (HSCs) and NK cells play important roles in the development of liver fibrosis. Upon liver damage, HSCs become "activated", proliferate and produce excessive extracellular matrix leading to the formation of the fibrotic scar (32). A recent study has shown that senescent activated HSCs, which can act to limit fibrosis progression, express significantly higher levels of immune modulators, such as MICA, than the proliferating activated HSCs; moreover, the senescent cells are selectively targeted by NK cells, potentially through interaction of the MICA ligand and NKG2D receptor (33). Several studies have demonstrated that various MICA family members are elevated in the sera of patients with autoimmune and cholestatic liver diseases (34-36). In the 3,5-diethoxycarbonyl-1,4-dihydrocollidine (DDC)-induced liver fibrosis model, NK cells ameliorate liver fibrosis by killing activated HSCs in an NKG2D-dependent manner (37).

The Hunan Han schistosomiasis patients with advanced liver fibrosis examined in our study had a higher frequency of the MICA*A5 allele. The MICA*A5 allele codes for a valine (V) amino acid at position 129 (IMGT/ HLA Database), while the MICA*A5.1 allele, also identified in our subjects, may possess either a methionine (M) or $\mathrm{V}$ at position 129. It has been shown that MICA M129 confers a higher affinity for the NKG2D receptor, whereas MICA V129 has reduced affinity (38). Therefore, a higher frequency of MICA*A5 may reflect more V129 products. In this situation, reduced engagement with the NKG2D receptor might lead to less activation of NK cells, and, subsequently, to less cytotoxicity against activated HSCs and more aggressive development of liver fibrosis. In contrast, the MICA*A5.1 allele, producing variant numbers of M129 and V129 products, would not be expected to push the NK-induced cytotoxicity to an extent that would favor either severe or mild liver fibrosis.

So far, few studies have compared MICA polymorphisms among distinct ethnic groups. We compared our genotyping result with those from other studies of different ethnic populations and showed that the distribution of MICA alleles does not differ dramatically among Han populations in different areas of China. However, the distribution is significantly different from that of all non-Chinese ethnic groups examined, implying that a differential susceptibility and progression of MICA-involved diseases exist among distinct ethnic groups.

Our data show that the MICA gene exhibits great variability among different ethnic groups. In the schistosomiasis-endemic Dongting Lake region, MICA*A5 positively correlates with the more severe phenotype of liver fibrosis in infected patients. Our findings will serve as a foundation 
for future in vitro and in vivo studies to elucidate the underlying immunopathological mechanisms associated with MICA-regulated liver fibrosis in S. japonicum infection.

\section{Acknowledgments}

We would like to thank Chief Nurse Gang Yuan for sample collection and all patients and healthy individuals

\section{References}

1. Chitsulo L, Engels D, Montresor A, Savioli L. The global status of schistosomiasis and its control. Acta Trop 2000; 77: 41-51.

2. Zhou D, Li Y, Yang X. Schistosomiasis control in China. World Health Forum 1994; 15: 387-389.

3. Wang L, Utzinger J, Zhou XN. Schistosomiasis control: experiences and lessons from China. Lancet 2008; 372: 1793-1795.

4. Zhou XN, Wang LY, Chen MG, Wu XH, Jiang QW, Chen XY, et al. The public health significance and control of schistosomiasis in China - then and now. Acta Trop 2005; 96: 97-105.

5. Wilson MS, Mentink-Kane MM, Pesce JT, Ramalingam TR, Thompson R, Wynn TA. Immunopathology of schistosomiasis. Immunol Cell Biol 2007; 85: 148-154.

6. Bahram S, Bresnahan M, Geraghty DE, Spies T. A second lineage of mammalian major histocompatibility complex class I genes. Proc Natl Acad Sci U S A 1994; 91: 62596263.

7. Groh V, Bahram S, Bauer S, Herman A, Beauchamp M, Spies T. Cell stress-regulated human major histocompatibility complex class I gene expressed in gastrointestinal epithelium. Proc Natl Acad Sci U S A 1996; 93: 12445-12450.

8. Choy MK, Phipps ME. MICA polymorphism: biology and importance in immunity and disease. Trends Mol Med 2010; 16: 97-106.

9. Zwirner NW, Dole K, Stastny P. Differential surface expression of MICA by endothelial cells, fibroblasts, keratinocytes, and monocytes. Hum Immunol 1999; 60: 323-330.

10. Zwirner NW, Fernandez-Vina MA, Stastny P. MICA, a new polymorphic HLA-related antigen, is expressed mainly by keratinocytes, endothelial cells, and monocytes. Immunogenetics 1998; 47: 139-148.

11. Ostberg JR, Dayanc BE, Yuan M, Oflazoglu E, Repasky EA. Enhancement of natural killer (NK) cell cytotoxicity by feverrange thermal stress is dependent on NKG2D function and is associated with plasma membrane NKG2D clustering and increased expression of MICA on target cells. J Leukoc Biol 2007; 82: 1322-1331.

12. Kloss M, Decker P, Baltz KM, Baessler T, Jung G, Rammensee HG, et al. Interaction of monocytes with NK cells upon Toll-like receptor-induced expression of the NKG2D ligand MICA. J Immunol 2008; 181: 6711-6719.

13. Chung-Ji L, Yann-Jinn L, Hsin-Fu L, Ching-Wen D, CheShoa C, Yi-Shing $L$, et al. The increase in the frequency of MICA gene A6 allele in oral squamous cell carcinoma. $J$ Oral Pathol Med 2002; 31: 323-328.

14. Elsner L, Flugge PF, Lozano J, Muppala V, Eiz-Vesper B, who generously provided the samples used in this study. We thank the Medjaden Bioscience Limited for assisting with the preparation of this manuscript. Research supported by grants from the National Natural Science Foundation of China (Project \#30870135) and the Eleventh Five-Year National Key Technology R\&D Program of China (Project \#2009BAI78B05).

Demiroglu SY, et al. The endogenous danger signals HSP70 and MICA cooperate in the activation of cytotoxic effector functions of NK cells. J Cell Mol Med 2010; 14: 992-1002.

15. Mei B, Luo Q, Du K, Huo Z, Wang F, Yu P. Association of MICA gene polymorphisms with Chlamydia trachomatis infection and related tubal pathology in infertile women. Hum Reprod 2009; 24: 3090-3095.

16. Zou Y, Bresnahan W, Taylor RT, Stastny P. Effect of human cytomegalovirus on expression of MHC class I-related chains A. J Immunol 2005; 174: 3098-3104.

17. Frigoul A, Lefranc MP. MICA: Standardized IMGT allele nomenclature, polymorphisms and diseases. Trivandrum, Kerala, India: Research Signpost; 2005.

18. Kimura A, Sasazuki T. Eleventh International Histocompatibility Workshop reference protocol for the HLA DNA-typing technique. New York: Oxford University Press; 1992.

19. Rees MT, Downing J, Darke C. A typing system for the major histocompatibility complex class I chain related genes $A$ and $B$ using polymerase chain reaction with sequence-specific primers. Genet Test 2005; 9: 93-110.

20. Zou Y, Han M, Wang Z, Stastny P. MICA allele-level typing by sequence-based typing with computerized assignment of polymorphic sites and short tandem repeats within the transmembrane region. Hum Immunol 2006; 67: 145-151.

21. Quiroga I, Sweeney D, Sutton PM, Ahmad T, Walton R, Barnardo MC, et al. The identification of three novel MICA alleles by sequence-based typing. Tissue Antigens 2006; 67: 321-325.

22. Tian W, Cai JH, Wang F, Li LX. MICA polymorphism in a northern Chinese Han population: The identification of a new MICA allele, MICA*059. Hum Immunol 2010; 71: 423-427.

23. Zhu F, Zhao H, He Y, Zhang W, He J, Xu X, et al. Distribution of MICA diversity in the Chinese Han population by polymerase chain reaction sequence-based typing for exons 2-6. Tissue Antigens 2009; 73: 358-363.

24. Pyo CW, Hur SS, Kim YK, Choi HB, Kim TY, Kim TG. Distribution of MICA alleles and haplotypes associated with HLA in the Korean population. Hum Immunol 2003; 64: 378-384.

25. Romphruk AV, Naruse TK, Romphruk A, Kawata H, Puapairoj C, Kulski JK, et al. Diversity of MICA (PERB11.1) and HLA haplotypes in Northeastern Thais. Tissue Antigens 2001; 58: 83-89.

26. Hirayama K. Immunogenetic analysis of post-schistosomal liver fibrosis. Parasitol Int 2004; 53: 193-196.

27. McManus DP, Ross AG, Williams GM, Sleigh AC, Wiest P, Erlich $\mathrm{H}$, et al. $\mathrm{HLA}$ class II antigens positively and negatively associated with hepatosplenic schistosomiasis in a Chinese 
population. Int J Parasitol 2001; 31: 674-680.

28. Czaja MJ, Weiner FR, Takahashi S, Giambrone MA, van der Meide PH, Schellekens $\mathrm{H}$, et al. Gamma-interferon treatment inhibits collagen deposition in murine schistosomiasis. Hepatology 1989; 10: 795-800.

29. Baroni GS, D’Ambrosio L, Curto P, Casini A, Mancini R, Jezequel AM, et al. Interferon gamma decreases hepatic stellate cell activation and extracellular matrix deposition in rat liver fibrosis. Hepatology 1996; 23: 1189-1199.

30. Henri S, Chevillard C, Mergani A, Paris P, Gaudart J, Camilla $\mathrm{C}$, et al. Cytokine regulation of periportal fibrosis in humans infected with Schistosoma mansoni: IFN-gamma is associated with protection against fibrosis and TNF-alpha with aggravation of disease. J Immunol 2002; 169: 929-936.

31. Comin F, Speziali E, Martins-Filho OA, Caldas IR, Moura V, Gazzinelli A, et al. Ageing and Toll-like receptor expression by innate immune cells in chronic human schistosomiasis. Clin Exp Immunol 2007; 149: 274-284.

32. Bataller R, Brenner DA. Liver fibrosis. J Clin Invest 2005; 115: 209-218.

33. Krizhanovsky V, Yon M, Dickins RA, Hearn S, Simon J, Miething $C$, et al. Senescence of activated stellate cells limits liver fibrosis. Cell 2008; 134: 657-667.
34. Mistry AR, O'Callaghan CA. Regulation of ligands for the activating receptor NKG2D. Immunology 2007; 121: 439-447.

35. Kohga K, Takehara T, Tatsumi T, Ohkawa K, Miyagi T, Hiramatsu N, et al. Serum levels of soluble major histocompatibility complex (MHC) class I-related chain A in patients with chronic liver diseases and changes during transcatheter arterial embolization for hepatocellular carcinoma. Cancer Sci 2008; 99: 1643-1649.

36. Jinushi M, Takehara T, Tatsumi T, Hiramatsu N, Sakamori $\mathrm{R}$, Yamaguchi $\mathrm{S}$, et al. Impairment of natural killer cell and dendritic cell functions by the soluble form of MHC class I-related chain A in advanced human hepatocellular carcinomas. J Hepatol 2005; 43: 1013-1020.

37. Radaeva S, Sun R, Jaruga B, Nguyen VT, Tian Z, Gao B. Natural killer cells ameliorate liver fibrosis by killing activated stellate cells in NKG2D-dependent and tumor necrosis factor-related apoptosis-inducing ligand-dependent manners. Gastroenterology 2006; 130: 435-452.

38. Kopp R, Glas J, Lau-Werner U, Albert ED, Weiss EH. Association of MICA-TM and MICB C1_2_A microsatellite polymorphisms with tumor progression in patients with colorectal cancer. J Clin Immunol 2009; 29: 545-554. 